\begin{tabular}{|c|c|c|}
\hline $\mathrm{Ar}$ & $\begin{array}{c}\text { European Association for the } \\
\text { Development of Renewable Energies, Environment } \\
\text { and Power Quality (EA4EPQ) }\end{array}$ & $\begin{array}{l}\text { International Conference on Renewable Energies and Power Quality } \\
\text { (ICREPQ'12) } \\
\text { Santiago de Compostela (Spain), 28th to 30th March, } 2012\end{array}$ \\
\hline
\end{tabular}

\title{
Modeling and Dynamic Analysis of Gearless Variable-Speed Permanent Magnet Synchronous Generator Based Wind Energy Conversion System
}

\author{
M. I. Marei and H. S. K. El-Goharey \\ Electrical Power and Machines Department \\ Faculty of Engineering, Ain Shams University \\ 1 El-Sarayat St., Abdo Basha sq., Abbassya, 11517 Cairo (Egypt) \\ e-mail: mostafamarei@yahoo.ca, hamdyk@hotmail.com
}

\begin{abstract}
This paper investigates the dynamic behavior of a gearless variable-speed Wind Energy Conversion System (WECS) based on Permanent Magnet Synchronous Generator (PMSG). Models and equation that describe different components of the WECS are addressed and their implementations into PSCAD/EMTDC are described. The control system of the back to back converters is developed for capturing the maximum energy from varying wind speed, regulating the DC-link voltage at a constant value, and maintaining reactive power generation at a pre-determined level which is zero in this study. Moreover, the pitch-angle controller is designed to regulate the machine speed at its rated value for high wind velocities. Simulation is performed in PSCAD/EMTDC software to evaluate the performance of different controllers and to study the dynamic behavior of the gearless WECS under varying wind speeds. This modeling study can be used for evaluating the control scheme, dynamic performance and impacts of a variable-speed WECS on the electrical grids.
\end{abstract}

\section{Key words}

Back to back converters, PMSG, WECS.

\section{Introduction}

During the last decades, Wind Energy Conversion System (WECS) has grown dramatically. Variable-speed wind turbines (VSWTs) attract considerable interest around the world, which is one of the solutions with the highest potential to reduce wind energy cost [1]. The VSWT systems are usually based on doubly fed induction generators (DFIGs) or permanent magnet synchronous generators (PMSGs). Direct-drive PMSG raises great interest because of its high efficiency and elimination of the gearbox [2]. Many power electronic converters are used to interface the PMSG with the grid. However, the most commercial WECSs are based on back to back voltage source converters [3].

This paper presents a detailed study of the dynamic performance of the gearless WECS based on PMSG. The interface system with the grid is based on back to back converters. The machine-side converter regulates the machine speed to absorb maximum power from the turbine. A simple Maximum Power Point Tracking (MPPT) technique is utilized. In addition, the pitch-angle controller is used to limit the machine speed at its rated speed during high wind incidents. Finally, the grid-side converter regulates the DC-link voltage by feeding the extracted power from the turbine to the grid. Moreover, it controls the reactive power fed to the grid. PSCAD/EMTDC software package is used to simulate the model of the WECS based on PMSG. The dynamic behavior of the turbine and the PMSG is analyzed to investigate the operation of the different control subsystems.

The paper is organized as follows. First, the system configuration and modeling of the variable-speed PMSG wind turbine is presented in section two. The control systems for the machine-side converter, grid-side converter, and the pitch angle are explained in section three. The results are analyzed and discussed in section four. Finally, section five concludes the paper.

\section{Modeling of the gearless wind turbine}

The main components of the gearless variable-speed WECS are the wind-turbine, the permanent magnet synchronous generator, the back to back converters with their control, and the pitch controller. A 1.3 MW directdrive WT unit is considered for this analysis [4].

\section{A. Wind turbine}

The turbine model is based on the steady-state power characteristics of the turbine. The friction factor and the inertia of the turbine are combined with those of the generator coupled to the turbine. The output power of the turbine is given by:

$$
P_{m}=0.5 \rho A C_{p} v_{w}^{3}
$$

where, $P_{m}$ is the mechanical output power of the turbine, $\rho$ is the air density $\left(\mathrm{Kg} / \mathrm{m}^{3}\right), A$ is the turbine swept area 


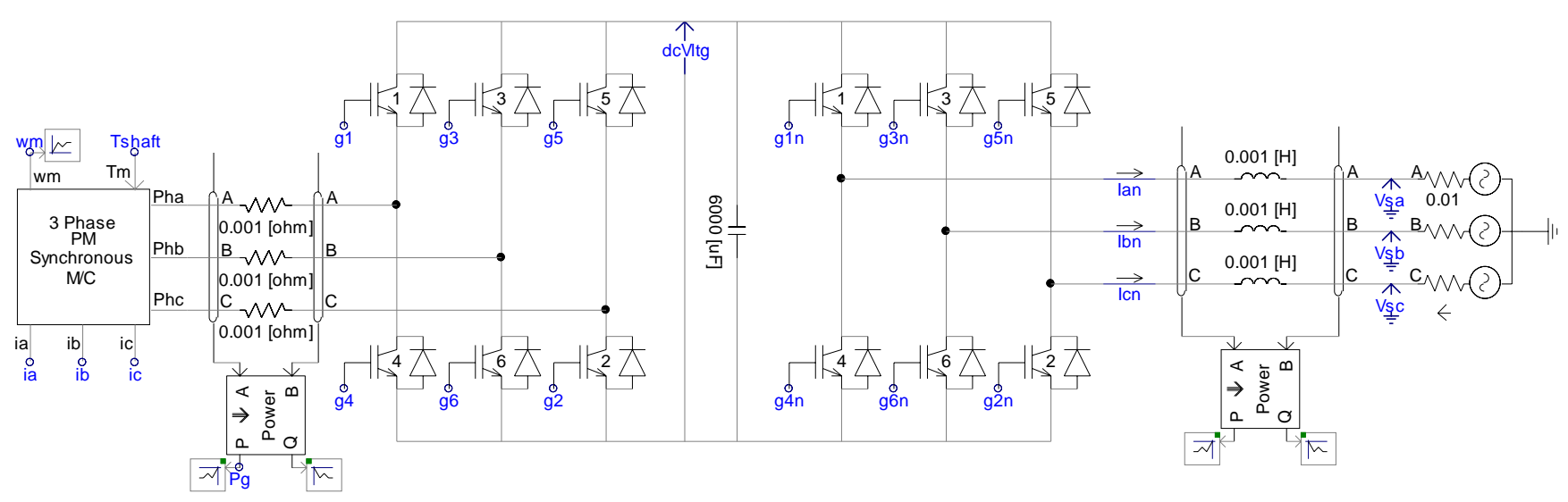

Fig. 1. Back to back converters for interfacing the PMSG with the grid.

$\mathrm{A} \approx \pi R^{2}, R$ is the blade radius (length), $C_{p}$ is the performance coefficient of the turbine, and $v_{w}$ is the wind speed $(\mathrm{m} / \mathrm{s})$.

The performance coefficient, $C p$, determines the power conversion efficiency from wind to mechanical. It is related to blade aerodynamic characteristics and turbine design. The performance coefficient is calculated from:

$$
\begin{gathered}
C_{p}=0.22\left(116 \lambda_{i}-0.4 \beta-5\right) e^{-12.5 \lambda_{i}} \\
\lambda_{i}=\frac{1}{\lambda+0.08 \beta}-\frac{0.035}{1+\beta^{3}}
\end{gathered}
$$

where: $\beta$ is the pitch angle (degree) and $\lambda$ is the tip speed ratio (TSR), defined by $\lambda=\omega_{m} R / V_{w}$. Finally, the output mechanical torque is calculated from:

$$
T_{m}=P_{m} / \omega_{m}
$$

where $\omega_{m}$ is the rotor angular speed $(\mathrm{rad} / \mathrm{sec})$.

\section{B. The Permanent Magnet Synchronous generator}

A third order model is used to represent the PMSG on PSCAD/EMTDC software package. The mathematical equations of the PMSG model in the rotor frame are:

$\frac{d}{d t}\left[\begin{array}{l}i_{d s}^{e} \\ i_{q s}^{e}\end{array}\right]=\left[\begin{array}{cc}-\frac{R_{s}}{L_{d}} & \frac{L_{q} P \omega_{m}}{L_{d}} \\ -\frac{L_{d} P \omega_{m}}{L_{q}} & -\frac{R_{s}}{L_{q}}\end{array}\right]\left[\begin{array}{l}i_{d s}^{e} \\ i_{q s}^{e}\end{array}\right]-\left[\begin{array}{c}\frac{v_{d s}^{e}}{L_{d}} \\ v_{q s}^{e}-P \omega_{m} \psi_{p m} \\ L_{q}\end{array}\right]$

where,

$i_{d s}^{e}, i_{q s}^{e}$ Stator direct and quadrature current components,

$v_{d s}^{e}, v_{q s}^{e}$ Stator direct and quadrature voltage components,

$R_{s}$ is the stator resistance, $L_{d}$ and $L_{q}$ are the direct and quadrature inductances, $P$ is the number of pole pairs, and $\Psi_{\mathrm{pm}}$ is the magnet flux (Weber).

The electromagnetic torque is given by:

$$
T_{e}=3 / 2 P\left(i_{q s}^{e} \Psi_{p m}+\left(L_{d}-L_{q}\right) i_{q s}^{e} i_{d s}^{e}\right)
$$

Finally, the electromechanical equation is written as:

$$
T_{m}-T_{e}=J d \omega_{m} / d t+B \omega_{m}
$$

where $J$ is the equivalent inertia of the machine and turbine, $B$ is the friction coefficient.

\section{The back to back converters}

The back to back converters, shown in Fig. 1, are used to connect the PMSG to the grid. The capacitor voltage must be regulated to avoid dangerous voltage rise which may damage the power electronics switches. The main function of the grid-side converter is to regulate the $\mathrm{dc}$ link voltage at a constant value. On the other hand, the machine side converter is used to extract the maximum power from the wind turbine and to regulate the rotational speed. A hysteresis current control technique is used for both converters [5], [6], as shown in Fig. 2.
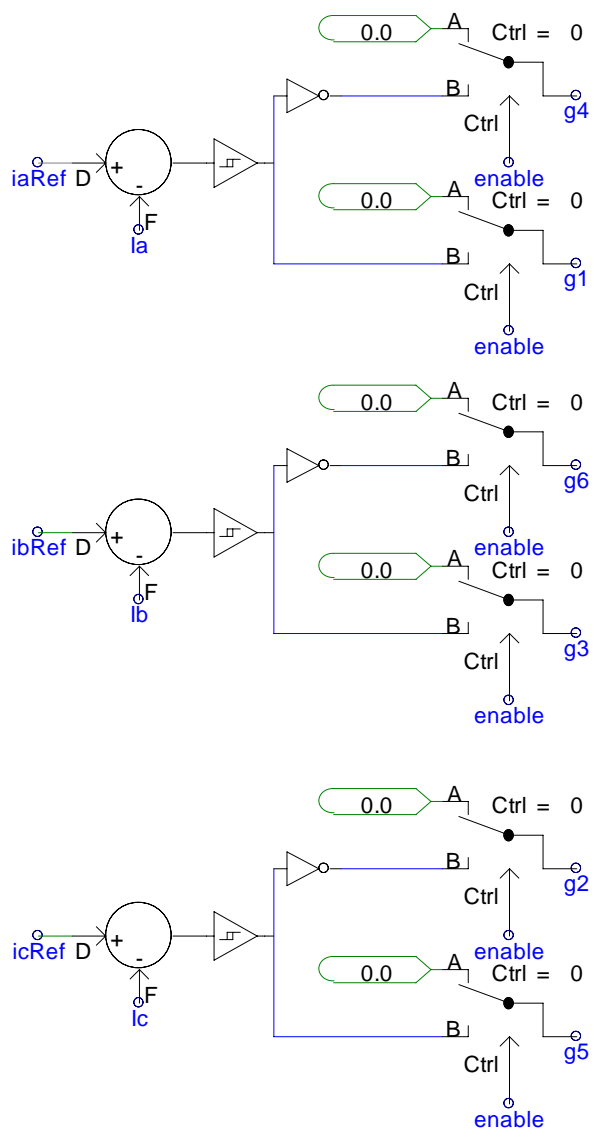

Fig. 2. Modeling of the hysteresis current control for the machine-side converter. 


\section{The proposed control system}

The control system of the gearless wind turbine is divided into three parts, which are described as in the following subsections.

\section{A. Control of the machine-side converter}

The machine-side converter is controlled to regulate the speed of the PMSG at a reference value that results in Maximum Power Point Tracking (MPPT). At zero pitch angle, the maximum power coefficient $C_{p}$ of the wind turbine, which varies with the TSR, $\lambda$, is 0.438 as calculated from (2) and (3). It occurs at an optimum TSR of 6.3. The MPPT technique is based on operating the turbine at its optimum TSR to get its maximum power at any incident wind velocity. Since $\lambda=\omega_{m} R / V_{w}$, the MPPT can be achieved by regulating the generator speed using the following equation:

$$
\omega_{\text {ref }}=\lambda_{\text {optimum }} V_{w} / R=6.3 V_{w} / 25=0.252 V_{w}
$$

The indirect rotor field oriented control is used for the machine-side converter [7]. Fig. 3 presents the block diagram of the control system of the machine-side converter. The speed reference, calculated from (8), is limited by the maximum angular speed of the generator/turbine, which is $3.5 \mathrm{rad} / \mathrm{sec}$. A PI controller is used to regulate the speed of the generator/turbine. The output of the PI controller is the quadrature current reference, iqref, for the PMSG. Zero current reference is assigned to the direct component of the stator current, idref, to achieve maximum torque/ampere capability. The d- and q- components are applied to the Park and Clarke transforms to generate the three-phase reference currents for the machine-side converter.

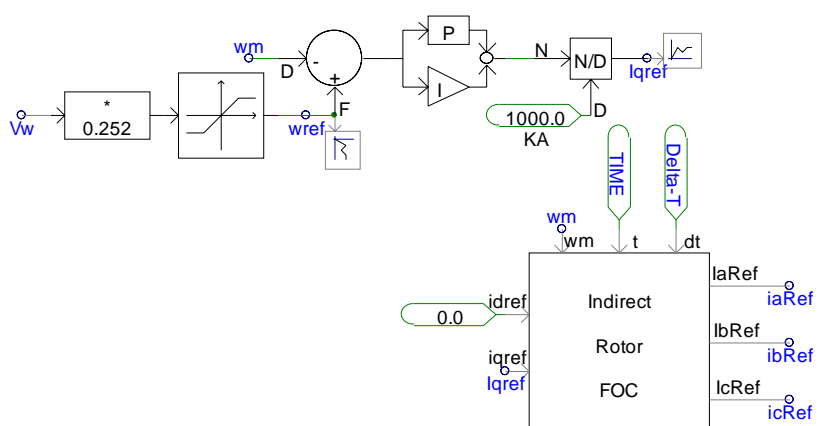

Fig. 3: Block diagram of the machine-side converter controller.

\section{B. Control of the grid-side converter}

The objective of the grid-side converter is to keep the DC link voltage constant regardless of the magnitude of the PMSG power. A vector-control approach is used with a reference frame oriented along the grid voltage vector position, enabling independent control of the active and reactive powers flowing between the grid and the grid-side converter.

Fig. 4 shows a block diagram of the control structure of the grid-side converter. The q-axis current component of the grid-side converter is used to regulate the DC link voltage,
dcVltg, at $1.3 \mathrm{Kv}$ using a PI controller. The d-axis component is used to control the flow of reactive power and is set to zero. Decoupled control of active and reactive powers flowing between the PMSG and grid is done by using grid voltage vector oriented control. A phase locked loop (PLL) circuit is used to calculate the space vector angle of the grid-voltage, theta. This angle is used for the inverse Park transformation of the $d$ and $q$ components of the grid-side converter to three-phase reference currents. These three-phase reference currents and the actual currents of the grid-side inverter are used by the current control of Fig. 2 to generate the corresponding firing signals for the switches to meet the current requirements.

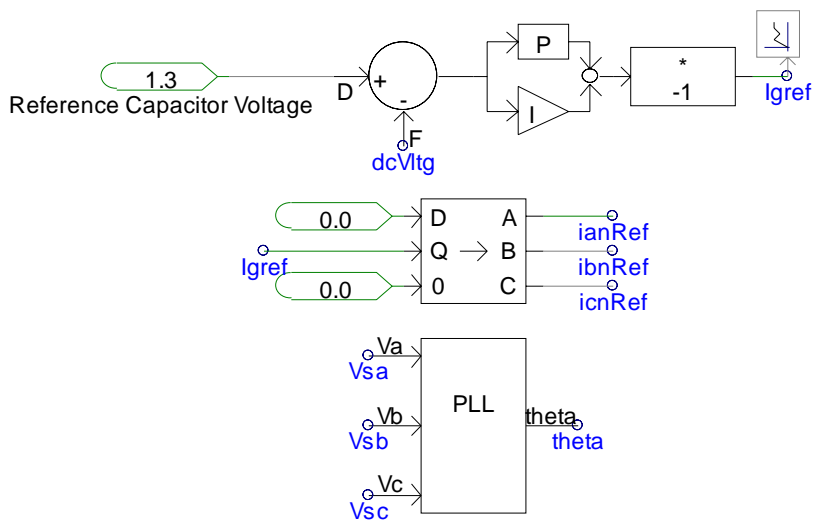

Fig. 4. Block diagram of the grid-side converter controller

\section{The Pitch-angle Controller}

When the maximum speed is reached, at the rated wind velocity, the pitch-angle controller is activated to reduce the available power from the turbine and hence the speed is regulated at its maximum limit. This action makes the generated power constant at wind velocities higher than the rated wind speed.

Fig. 5 shows the block diagram of the pitch-angle controller. It is based on a PI controller to process the error between the angular speed of the turbine/generator and the rated value. The output from the PI controller is the pitch angle, BetaRef. Below rated angular velocity, the input to the PI controller is zero to deactivate the controller, $\beta=0$. A rate limiter of 10 degree/sec. is used to prevent sudden motion of the blades [8].

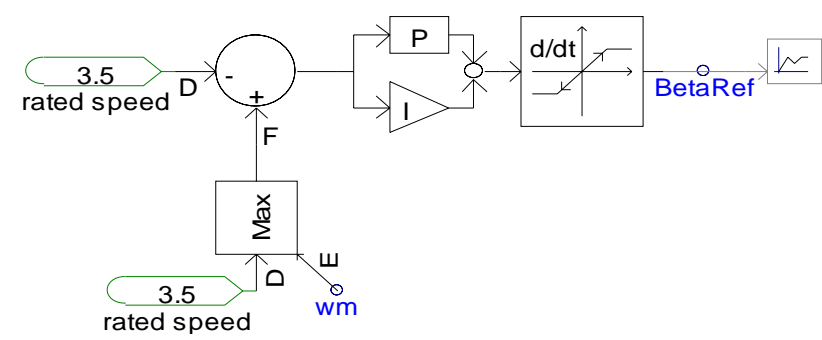

Fig. 5. Block diagram of the pitch-angle controller

\section{Simulation Results}

Fig. 6 explores the dynamic behavior of the proposed direct-drive wind turbine system. The wind velocity is 
hypothetically changed with time according to the sequence drawn in Fig. 6(e). The MPPT controller calculates the optimum reference for the generator speed as shown in Fig. 6(b). The machine-side converter succeeds in regulating the generator speed at its optimum variable setting from the MPPT. This action results in extracting the maximum power from the wind turbine as shown in Fig. 6(c). Fig. 7 portrays the trajectory of the turbine power and speed, which clarifies and explains the maximum power tracking process. During any interval of constant wind velocity, the reference rotor speed for maximum power tracking is determined. The operating point $(\mathrm{P}$ and $\omega)$ is moved along a corresponding turbine power-speed characteristic (power curve) and is tracked by the controller of the machine-side converter until the point of maximum power is achieved. These traces are parts of the turbine characteristics shown in Fig. 8. If the wind velocity changes, the generator side converter fixes the reference rotor speed to a new value which corresponds to maximum power tracking, and another power curve will be followed until maximum power is reached. This process is continued until the PMSG reaches its rated speed at a wind velocity higher than the rated value $(13.5 \mathrm{~m} / \mathrm{s})$. At this wind velocity, the pitch controller is activated to reduce the turbine speed and hence the power. This can be observed from Fig. 9 which is a zoom of Fig. 7 that focuses on the trajectory of the mechanical power when the wind velocity is changed from $13.4 \mathrm{~m} / \mathrm{s}$ to $15 \mathrm{~m} / \mathrm{s}$. The steady state operating point at wind velocity of $13.4 \mathrm{~m} / \mathrm{s}$ is $\mathrm{P} 1$, while $\mathrm{P} 2$ is the operating point at wind speed of $15 \mathrm{~m} / \mathrm{s}$.

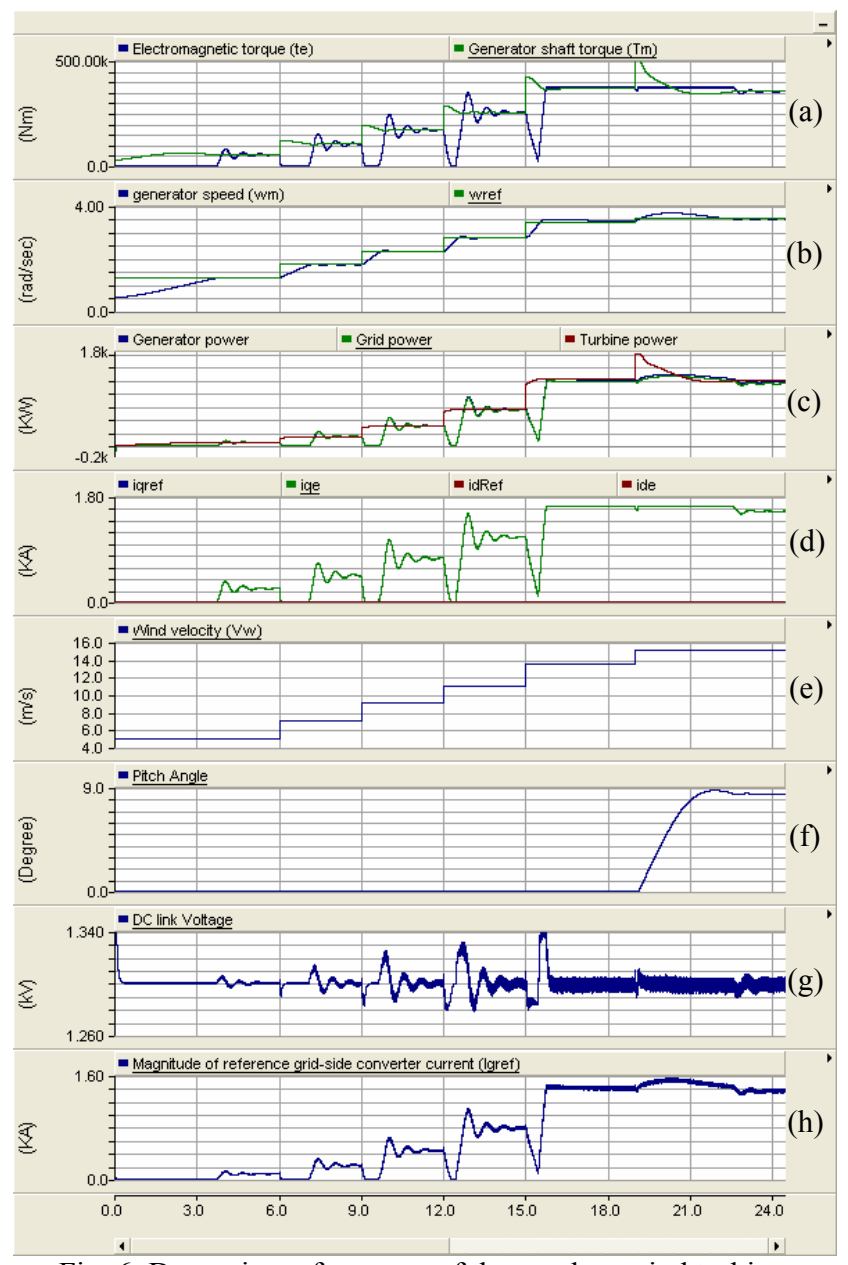

Fig. 6: Dynamic performance of the gearless wind turbine.

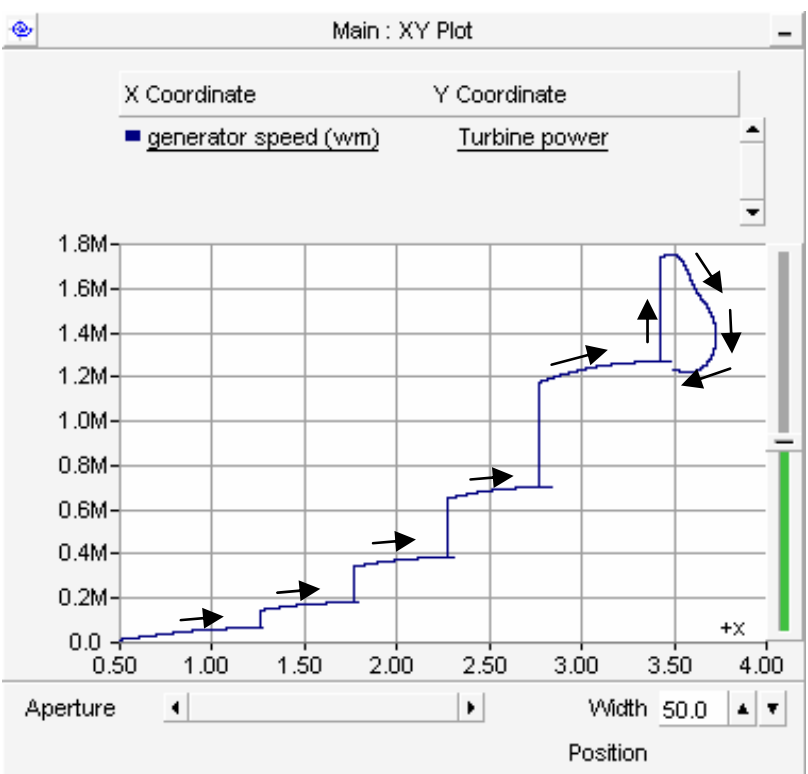

Fig. 7: Trajectory of turbine power and speed for the first 24 seconds of the simulation.

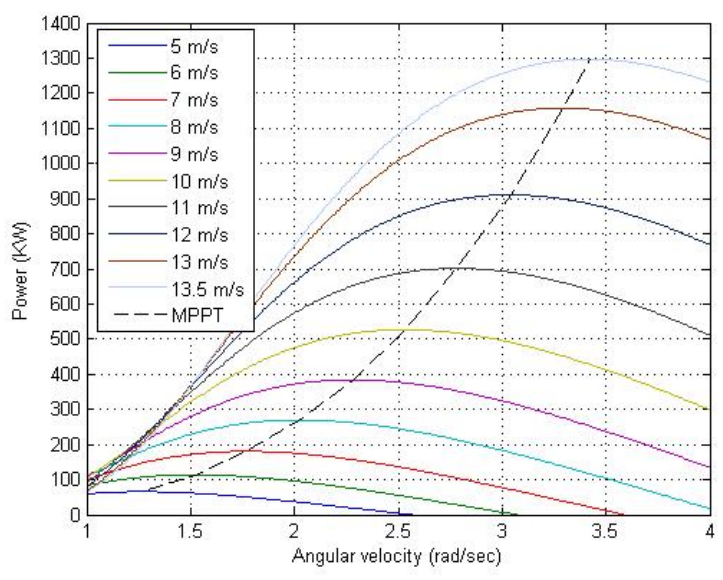

Fig. 8: Characteristics of the wind turbine.

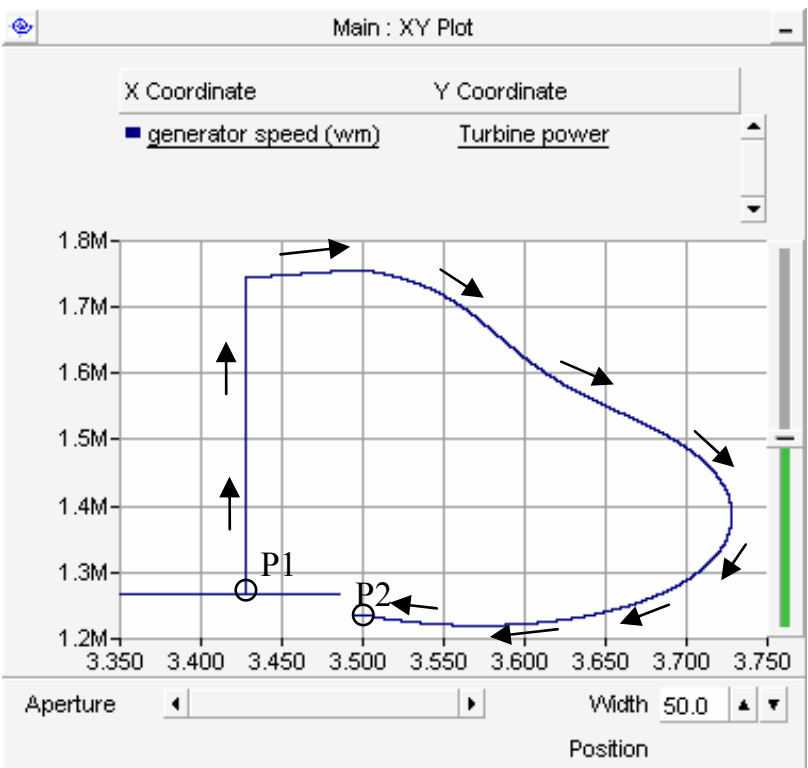

Fig. 9: Trajectory of turbine power and speed when the wind velocity is changed from $13.4 \mathrm{~m} / \mathrm{s}$ to $15 \mathrm{~m} / \mathrm{s}(\mathrm{t}=18 \mathrm{~s}$. to $\mathrm{t}=24 \mathrm{~s})$.

As expected, the pitch controller is continuously adjusting the pitch angle, as shown in Fig. 6(f), to 
regulate the angular speed at $3.5 \mathrm{rad} / \mathrm{sec}$. As a result of this operation, the mechanical power extracted from the wind turbine is very close to the rated value of the generator.

Fig. 6(d) shows the action of the current controller as it displays both the d- and q-axis current components (iqe and ide respectively) of the machine-side converter. It reveals that iqe coincides with its reference value, iqref, and ide is regulated at zero value. Fig. 6(a) portrays both the turbine and electromagnetic torques of the PMSG. The figure shows the proportionality between the electromagnetic torque and the q-axis current component. For any increase in wind velocity, the turbine power is increased and hence the mechanical torque. The machineside converter reduces the electromagnetic torque to zero to maximize the accelerating torque to reach the optimum rotational speed. Once the generator speed is regulated at the optimum value, the accelerating torque is diminished and the electromagnetic torque becomes equal to the mechanical torque of the turbine.

The grid-side converter regulates the dc-link voltage at its desired reference value of $1.3 \mathrm{kV}$, Fig. $6(\mathrm{~g})$. The voltage regulation is achieved by transferring the variable power of the generator to the grid. This has been done by controlling the reference current of the machine-side converter, Igref. Fig. 6(c) shows that the difference between the generator and grid powers is very small, which represents the losses in the back-to-back converters. Fig. 6(c) and (h) indicate that the grid power and the reference current of the gridside converter exhibit similar shapes. Also, Fig. 6(d) and (h) show that the torque producing current component of the PMSM (q-axis current component iqe) and the reference current of the grid-side converter (Igref) have similar shapes, except when the wind speed exceeds its rated value $(\mathrm{t}>18 \mathrm{sec})$ when iqe is limited to the rated value of the PMSG current.

Fig. 10 shows a snapshot for the dynamic behavior of the direct-drive wind turbine system following the occurrence of two wind speed changes; a small change from 15 to $15.2 \mathrm{~m} / \mathrm{s}$ at $\mathrm{t}=25 \mathrm{~s}$, and a large change from 15.2 to $16 \mathrm{~m} / \mathrm{s}$ at $t=29 \mathrm{~s}$. The purpose of the study is to focus on the coordination between the controllers of the machine-side converter and the pitch-angle. For the case of small wind speed change, the machine-side converter regulates the generator speed to its limit ( $3.5 \mathrm{rad} / \mathrm{s})$, without the need for pitching more the turbine blades, Fig. 10(f), only if the quadrature current component (power producing component) doesn't exceed its limit value. This situation is shown in Fig. 10(d) where the speed regulation is done by controlling iqe as long as it doesn't reach its current limit value. On the other hand, for large wind speed change above the rated wind speed, where iq is saturated at its limit value as shown in Fig. 10(d), the pitch controller acts to keep the generator speed fixed at its rated value as shown from Fig. 10(b) and (f). At steady-state and for both types of disturbances, the grid power is less than the generator power, and the latter is less than the turbine power, Fig. 10(d). The difference between the turbine and generator powers is the mechanical losses, while the difference between the generator and grid powers is the electrical losses. In summary, the machine-side converter takes over control for small wind speed changes as long as the q-axis reference current, iqref, is less than its limit. For large wind speed changes, the pitch-angle controller takes the action of regulating the turbine/generator speed by increasing the pitch angle, as Iqref of the machine-side converter reaches its limit value.

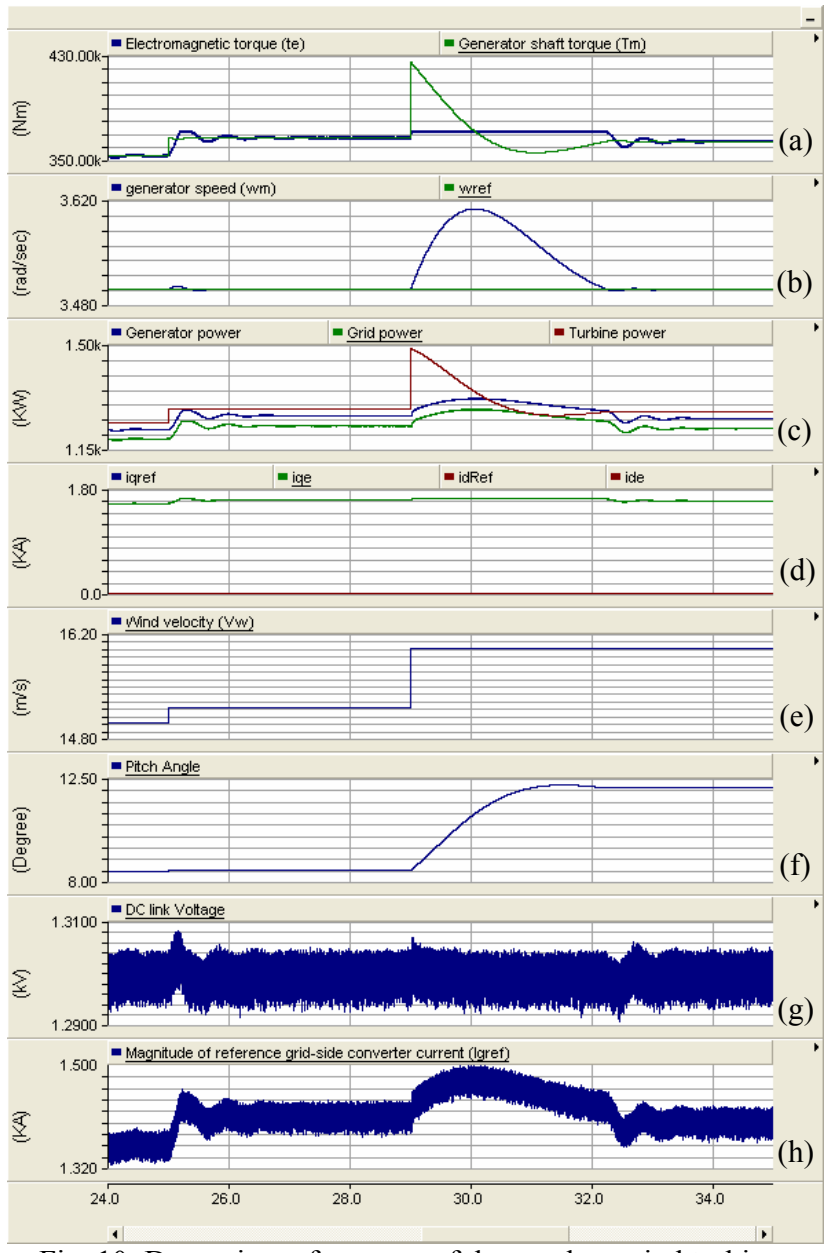

Fig. 10: Dynamic performance of the gearless wind turbine system at high wind velocities.

Fig. 11 and 12 show the turbine power/speed trajectory for both small and large wind speed disturbances. These figures support the interpretation given above for the action of the controllers. In Fig. 11, following the occurrence of small wind speed disturbance, the system operating point moves directly upward from P2 to P3, which means that the generator provides higher power at constant generator speed $(\mathrm{w}=$ wref $=3.5 \mathrm{~m} / \mathrm{s}$ ). This demonstrates the action of the controller of the machineside converter. Fig. 12 reveals that, following the occurrence of a large wind speed change, the operating point P3 moves cyclically to P4, which is vertically below P3. This demonstrates the interference of the pitch control system which maintains the turbine power constant and regulates the generator speed such that $\mathrm{w}=$ wref.

Finally, the grid-side converter continuously regulates the dc-link voltage, Fig. 10(g), and transfers the extracted maximum power to the grid. The magnitude of the gridside converter current, Fig. 10(h) follows the shape of the PMSG power, Fig. 10(c).

Figure 13(a) shows a snapshot of the PMSG (machineside converter) current. Fig. 13(b) illustrates that the grid-side converter current is in phase with the grid voltage; hence no reactive power is supplied to the grid. 


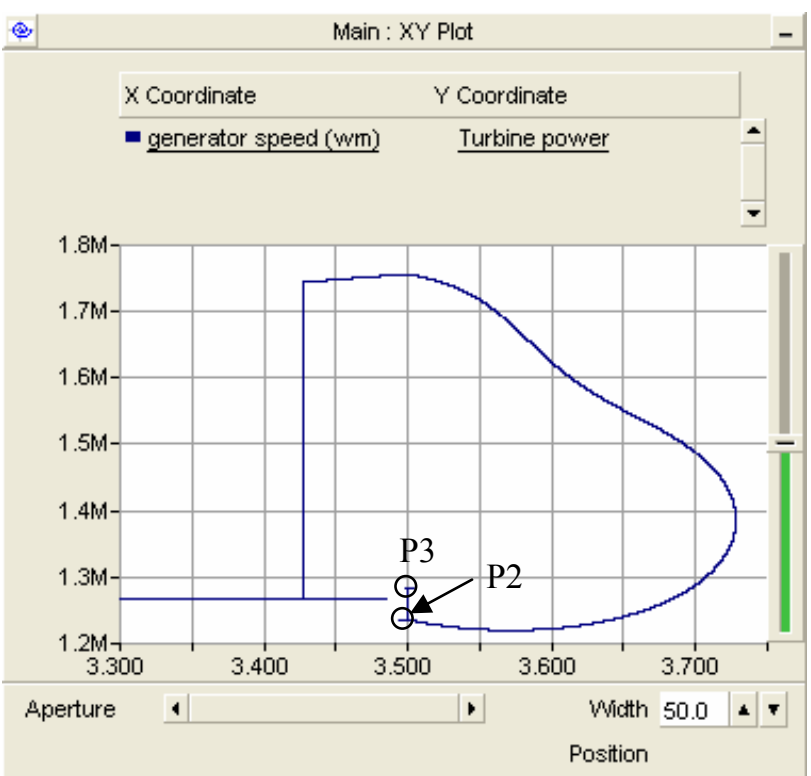

Fig. 11: Trajectory of turbine power and speed when the wind velocity is changed from $15 \mathrm{~m} / \mathrm{s}(\mathrm{P} 2)$ to $15.2 \mathrm{~m} / \mathrm{s}(\mathrm{P} 3)$.

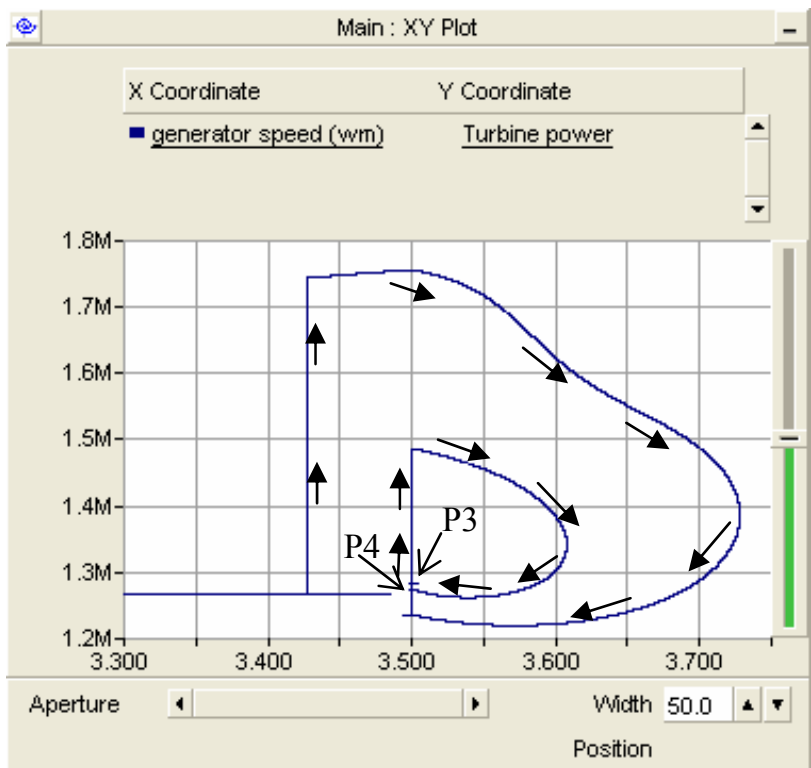

Fig. 12: Trajectory of turbine power and speed when the wind velocity is changed from $15.2 \mathrm{~m} / \mathrm{s}(\mathrm{P} 3)$ to $16 \mathrm{~m} / \mathrm{s}(\mathrm{P} 4)$.

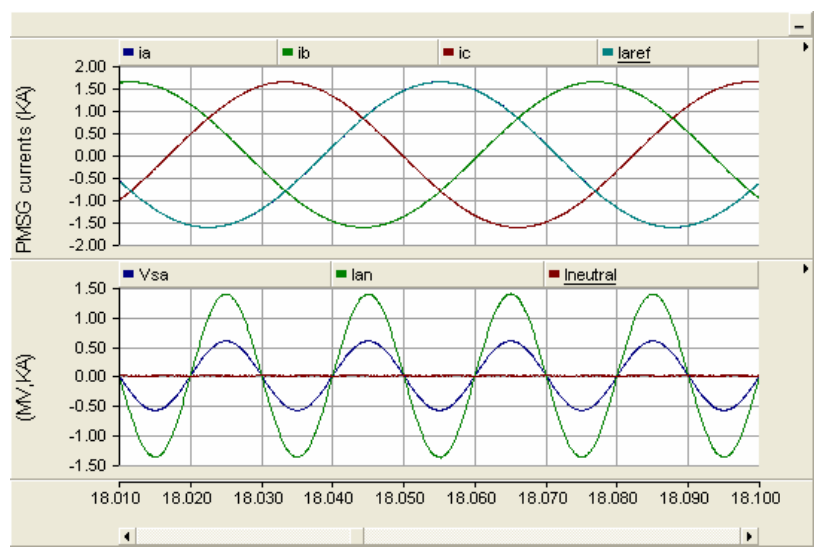

Fig. 13: The currents of the PMSG and the grid-side converter.

This agrees with the setting for zero reactive power on the grid-side converter. The current of both converters are sinusoidal and tracks their references. The previous results prove the effectiveness of the converter controller performance.

\section{Conclusion}

The paper presents a detailed model for gearless variablespeed WECS based on PMSG. This model is simulated on PSCAD/EMTDC software package. The dynamic performance of the machine-side converter, the grid-side converter, and the pitch-angle controllers are investigated. The trajectories of the turbine power and speed illustrate the action of the MPPT controller of the machine-side converter. The operating point is moved along the turbine power-speed characteristics and is tracked by the machine-side converter until the point of maximum power is achieved. The results demonstrate the coordination between the controllers of the machine-side converter and the pitch-angle. The machine-side converter takes over controlling the generator speed as long as the q-axis reference current is less than its limit. The pitch-angle controller takes the action of regulating the turbine/generator speed as the current of the machineside converter reaches its limit value. The presented model can be used for investigating the dynamic interactions between variable-speed WECS and the grid.

\section{Acknowledgement}

This project was supported financially by the Science and Technology Development Fund (STDF), Egypt, Grant No 1496.

\section{References}

[1] Z. Chen, J. Guerrero, and F. Blaabjerg, "A review of the state of the art of power electronics for wind turbines," IEEE Transactions on Power Electronics, vol. 24, no. 8, pp. 1859-1875, Aug. 2009.

[2] H. Polinder, F. van der Pijl, G.-J. de Vilder, and P. Tavner, "Comparison of direct-drive and geared generator concepts for wind turbines," IEEE Transactions on Energy Conversion, vol. 21, no. 3, pp. 725-733, Sept. 2006.

[3] X. Tan, J. Dai, and B. Wu,“A Novel Converter Configuration for Wind Applications Using PWM CSI with Diode Rectifier and Buck Converter" IEEE International Electric Machines \& Drives Conference (IEMDC), pp. 359364, 2011.

[4] ZU Hui, ZHANG Guo-Bao, FEI Shu-Min, WEI Zi-Cong, Zhu Hai-Rong, and FEI Shu-min, " $\mathrm{H}_{\infty}$ Robust Control of Direct-Drive Permanent Magnetic Synchronous Generator Considering the Uncertainty of Stator Parameters," Proceedings of the 30th Chinese Control Conference, July 22-24, 2011, Yantai, China.

[5] D. M. Bord and D. W. Novotony, "Current control of VSIPWM inverters", IEEE Trans. On Ind. Appl., Vol. 21, pp 562-570, May/June 1985.

[6] L. Malesani and P. Tenti, "A Novel hysteresis control method for current-controlled voltage-source PWM inverters with constant modulation frequency ", IEEE Trans. on Ind. Appl, Vol. 26, pp 88-92, Jan./Feb. 1990.

[7] P. Vas, Sensorless vector control and direct torque control, Oxford Press, New York (1998).

[8] A. Uehara, A. Pratap, T. Goya, T. Senjyu, A. Yona, N. Urasaki, and T. Funabashi, "A Coordinated Control Method to Smooth Wind Power Fluctuations of a PMSG-Based WECS" IEEE Transactions on energy conversion, vol. 26, no. 2, June 2011. 